\title{
The Teaching of Applied Mechanics through Textbooks in Italy
}

\author{
Marco Cocconcelli \\ Department of Sciences and Methods of Engineering, University of Modena and Reggio Emilia, Reggio Emilia, Italy \\ Email: marco.cocconcelli@unimore.it
}

How to cite this paper: Cocconcelli, M. (2020). The Teaching of Applied Mechanics through Textbooks in Italy. Advances in Historical Studies, 9, 358-376.

https://doi.org/10.4236/ahs.2020.95027

Received: October 30, 2020

Accepted: December 7, 2020

Published: December 10, 2020

Copyright (c) 2020 by author(s) and Scientific Research Publishing Inc. This work is licensed under the Creative Commons Attribution International License (CC BY 4.0).

http://creativecommons.org/licenses/by/4.0/ (c) (i) Open Access

\begin{abstract}
In this paper, the evolution of the teaching of Applied Mechanics in Italy is detailed. A particular point of view is considered, that is the textbooks published from the postwar period to the present day. In the educational process of a student, textbooks implicitly define the subject of study and are the reference book the student will keep throughout the career. Despite the foundations of Applied Mechanics date back to Renaissance, the way it is transmitted to students evolves over time, especially in the last fifty years. This study does not pretend to be complete but it correlates the main changes in the textbooks of Applied Mechanics to the historical changes in the Italian University system. An original classification is proposed to clustering publications that exhibit the same characteristic features. In particular, three "periods" are identified: the Masters (1945-1980), the Schools (1980-2000) and the Courses (2000-today). Each period is strictly correlated to significant reform of the Italian University system. It is stressed that the classification into the three proposed classes must be made based on the contents of the text and not purely on the date of publication.
\end{abstract}

\section{Keywords}

Applied Mechanics, Italian University, Textbooks

\section{Introduction}

This invited paper is an extended and revised version of a previous work submitted by the author to the Third International Conference of IFToMM Italy, held on September 9-11, 2020 (Cocconcelli, 2021). IFToMM Italy is the Italian member organization of the International Federation for the Promotion of Mechanism and Machine Science (IFToMM). Its mission is to promote research and development in the field of Machines and Mechanisms by theoretical and 
experimental methods, along with their practical application (IFToMM, 2020). In particular, the history of mechanism and machine science is an integral part of the association's aims. This paper focuses on the history of the teaching of Applied Mechanics in Italy. The Italian name is "Meccanica Applicata Alle Macchine" and taught in different degree courses in Engineering. More details will be given in the next sections. This historical excursus has been made through a particular point of view, i.e. the reference textbooks in the academic course of Applied Mechanics. This choice is supported considering the learning process of a student that it is made of two main tools: the live lectures and the reference textbooks. If the formers are indispensable in the short term to build the foundation of the subject of study, the latter are a reference tool that the student will carry with him/her throughout the career. On the long run, textbooks will represent a tangible realization of the academic course, to which to return if there are doubts or to seek support. From this perspective, textbooks define the matter itself and a historical analysis of them coincides with that of the scientific matter they deal with. In literature, fundamental contributions on the history of Applied Mechanics are given by Della Pietra (Della Pietra, 2006) and Ceccarelli (Ceccarelli, 2014).

In particular, Della Pietra focuses on the history of Applied Mechanics at the University of Naples "Federico II", comparing textbooks proposed at the University of Naples (Ferretti, 1966) and at the Politecnico di Milano (Sesini, 1946) from 1960 to 2003. Conversely, Ceccarelli focuses on the history of Applied Mechanics, but intended as a scientific sector rather than teaching subject. Nevertheless, the paper of Ceccarelli clearly details the birth and the evolution of Applied Mechanics from Renaissance to date, providing information that are the foundations of this manuscript (e.g. the texts of the declaratory statements and the evolution of Applied Mechanics in modern era). The secondary purpose of this paper is collecting the main publications of the Italian community of Applied Mechanics from the 1940 to 2020. Unlike scientific papers, the lifetime of textbooks is limited to the interest of the publisher and the risk that they will be forgotten over time is high. Indeed, the number of publications has been increasing up to the present day, as well as the number of topics covered. As a consequence, few boundary conditions have been used in this work:

- Only published textbooks have been included, i.e. lecture notes were not considered, although they are made available on the University website.

- Exercise books were not included, only theory textbooks.

- Only textbooks related to the fundamental course of Applied Mechanics have been included. Books on specialized courses are recalled if necessary, e.g. to better detail the characteristic features of a period, but an exhaustive list of these publications is out of the scopes.

The history and development of Applied Mechanics textbooks went hand in hand with that of the Italian university system. Common features can be found in textbooks following the introduction of reforms in the university system. In 
this paper, three main periods of time have been proposed to identify milestones in the history of Applied Mechanics, each one as a result of significative changes in the university systems. These periods are named "the masters" (1945-1980), "the schools" (1980-2000) and "the courses" (2000-today). It is worth noting that the years interval is only indicative, as the boundaries between one period and the next are not clear but slowly passed from one to another. Conversely, characteristic features of the textbooks classify them in the proper period.

The structure of the paper is the following: Section 2 details what the Applied Mechanics is, its research areas and the contribution given by Prof. Modesto Panetti to the born of the Applied Mechanics in Italy. Sections 3, 4 and 5 deal with the periods proposed ("the masters", "the schools" and "the courses" respectively). Each one presents a short historical background and the characteristics of the period. Future prospects are given in Section 6 before the conclusions.

\section{Applied Mechanics (ING-IND/13)}

In the Italian University, all the academic disciplines are listed and classified into specific classes called Disciplinary Scientific Sector (SSD is the Italian acronym). This disciplinary distinction is used to organize higher education and the current revised list is established by the ministerial decree of 30 October 2015, n. 855 of the Italian government. The scientific-disciplinary sectors (SSD) are 367, corresponding to 188 competition sectors (SC), 88 macro-sectors and 14 areas (Universitaly, 2020). The areas are at the top level of the classification and they cover all the academic knowledge: starting from Mathematics and Informatics (area 01), through Medicine (area 06), Industrial and information engineering (area 09) to Political and social sciences (area 14). Each area is then classified into three-levels of subclasses, that details better the specific thematic field of interest. The SSD is the most specific subclass. An example of this classification is reported in Table 1 for the area $01-$ Mathematics and informatics. Each professor and researcher that works in the Italian University is classified into a single SSD, based on his/her research activity. The habilitation to academic roles and teaching activities has the aim of verifying the candidate's preparation and the coherence of the research activity with the topics of the SSD for which he/she is competing.

This paper focuses on a specific SSD: the ING-IND/13-Applied Mechanics, within the area 09-Industrial and information engineering, the macro sector $\mathrm{A}-$ Mechanical, aerospace and naval engineering and the competition sector A2Applied Mechanics. This SSD is a compulsory course for classes of bachelor degree in Industrial design, Information engineering and Industrial Engineering, and for classes of master degree in Design, Automation engineering, Mechanical engineering and Mathematical-physical modeling for engineering. The ING-IND/13 focuses on the application of classic Mechanics (i.e. kinematics, statics and dynamics) to engineering problems. Applied Mechanics emerged as the integration (synthesis) of Analytical Mechanics with Engineering Sciences, which received 
Table 1. Example of SSD classification in italian university system (Universitaly, 2020).

\begin{tabular}{|c|c|c|c|}
\hline Area & Macro Sectors & Competition Sectors & SSD \\
\hline \multirow{7}{*}{$\begin{array}{l}\text { 01-Mathematics } \\
\text { and Informatics }\end{array}$} & \multirow{6}{*}{ 01/A-Mathematics } & $\begin{array}{c}\text { 01/A1-Mathematical } \\
\text { logic and complementary } \\
\text { mathematics }\end{array}$ & $\begin{array}{l}\text { MAT/01- Mathematical } \\
\text { logic } \\
\text { MAT/04-Mathematic edu- } \\
\text { cation and history } \\
\text { of mathematics }\end{array}$ \\
\hline & & $\begin{array}{c}\text { 01/A2-Algebra and } \\
\text { geometry }\end{array}$ & $\begin{array}{l}\text { MAT/02-Algebra } \\
\text { MAT/03-Geometry }\end{array}$ \\
\hline & & $\begin{array}{l}\text { 01/A3-Mathematical } \\
\text { analysis, probability } \\
\text { and statistics }\end{array}$ & $\begin{array}{l}\text { MAT/05-Mathematical } \\
\text { analysis } \\
\text { MAT/06-Probability } \\
\text { and statistics }\end{array}$ \\
\hline & & $\begin{array}{c}\text { 01/A4-Mathematical } \\
\text { physics }\end{array}$ & $\begin{array}{c}\text { MAT/07-Mathematical } \\
\text { physics }\end{array}$ \\
\hline & & $\begin{array}{c}\text { 01/A5-Numerical } \\
\text { analysis }\end{array}$ & $\begin{array}{l}\text { MAT/08-Numerical } \\
\text { analysis }\end{array}$ \\
\hline & & $\begin{array}{l}\text { 01/A6-Operational } \\
\text { research }\end{array}$ & $\begin{array}{l}\text { MAT/09-Operational } \\
\text { re-search }\end{array}$ \\
\hline & 01/B-Informatics & 01/B1-Informatics & INF/01-Informatics \\
\hline
\end{tabular}

an incredible impetus for development during the industrial revolution. In Italy, it is worth noting the birth of large industries like Breda (1840), Riva Calzoni (1861), Franco Tosi (1876), Borletti (1895) and more (Biggioggero \& Rovida, 2014). An exhaustive list of the research topics could be found in the declaratory that is a document filed by a dedicated scientific committee and accepted by the ministry of education. The current revised declaratory of the ING-IND/13-Applied Mechanics is reported in Table 2.

With reference to the many fields of application the Applied Mechanics deals with, these are mainly intended as research areas and it is evident the influence of modern challenging themes like bio-engineering, micro/nano scale devices, mechatronics, etc. Focusing on foundations of Applied Mechanics, the declaratory states that the sector includes the study of mechanical systems, machines and their components and structures, i.e. the develop of tools for the analysis and synthesis of machines and mechanisms. The research topics mainly fall within the field of Mechanical Engineering, and within the scope of international organizations like the International Federation for the Promotion of Mechanism and Machine Science (IFToMM). Indeed, different Applied Mechanics members contributed to the development of the IFToMM. Giovanni Bianchi (Politecnico di Milano) was one of the founders in 1969 and President (1984-1991). Alberto Rovetta (Politecnico di Milano) has been member of Executive Council, while Marco Ceccarelli (University of Rome Tor Vergata) has been president of IFToMM for two terms (2008-2011, 2016-2019) (IFToMM, 2020). 
Table 2. Declaration and competences of Applied Mechanics-2013 (Ceccarelli, 2014).

\begin{tabular}{|c|c|}
\hline Year & Text of Declaratory \\
\hline 2013 & 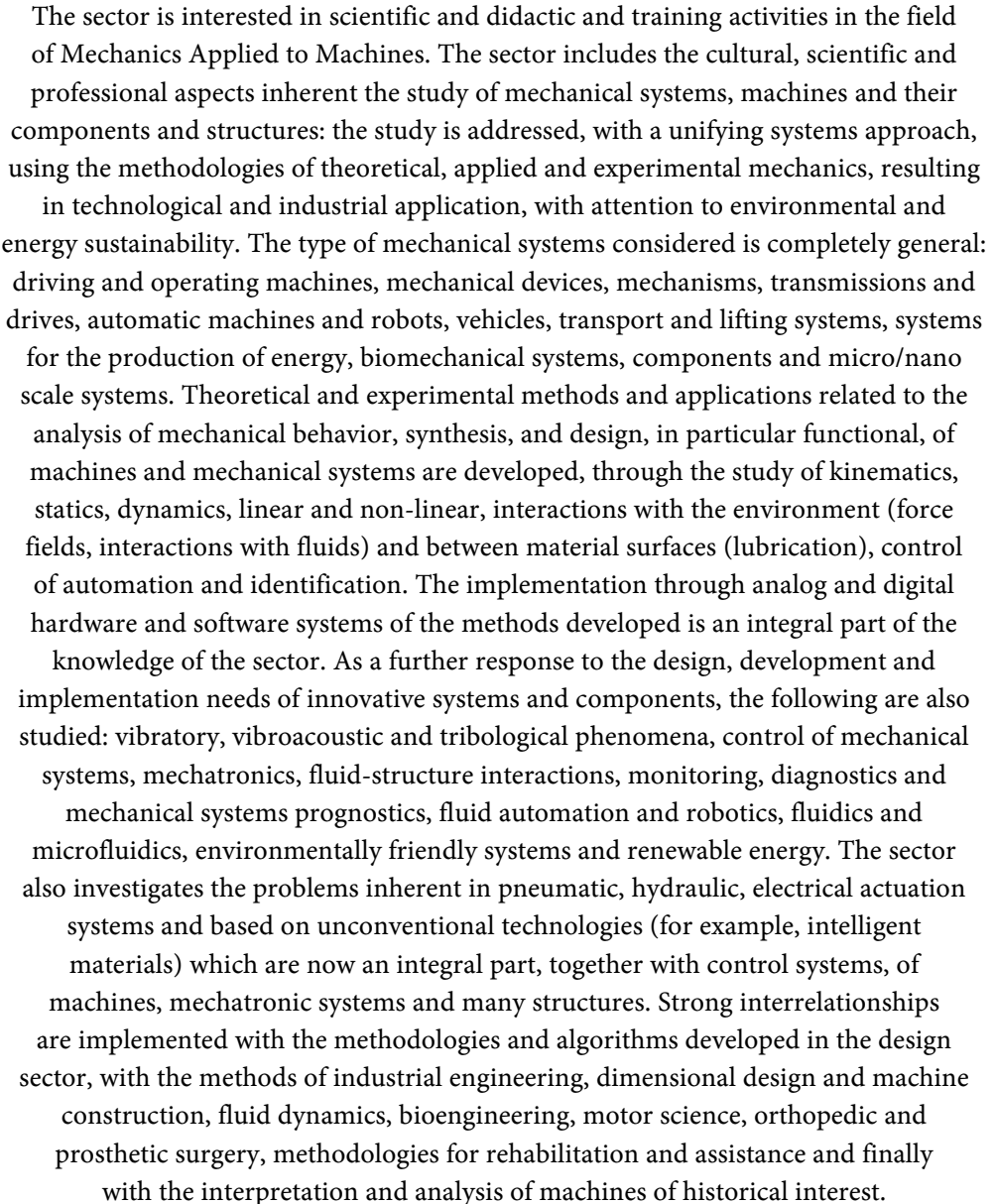 \\
\hline
\end{tabular}

The academic course named Applied Mechanics provides these foundations to the students, referring to specialized courses the teaching of advanced matters. From an historical point of view, the born of the Applied Mechanics dates back to October 17th 1860, when a royal decree introduced the teaching of Applied Mechanics at the two-years course of the Scuola di Applicazione per gli Ingegneri in Turin (Biggioggero \& Rovida, 2014; Meneghetti, 2016) (Technical school for engineers is the literal translation).

\subsection{Modesto Panetti (1875-1957)}

A leading figure in the field of teaching Applied Mechanics is that of professor Modesto Panetti (February 9, 1875-March 26, 1957). According to Funaioli (Funaioli, 1998) "professors of the previous generation had made important contributions to the course of Applied Mechanics: just mention Pistolesi in Pisa and Prosciutto in Bologna. But the founding father of the Applied Mechanics course in Italy was Modesto Panetti, who had given the course true university dignity and solid scientific foundations. Panetti, born in 1875, was almost a generation 
older than the Pistolesi and Prosciutto and was directly or indirectly their master". Panetti graduated from the Technical School for Engineers in 1896, with a specialization in Electrical Engineering and in 1899 he graduated in Mathematics. Professor of Rational and Applied Mechanics at the Naval School of Genoa in 1902, in 1910 he was invited to the Politecnico di Torino as full professor of Applied Mechanics. Since 1912 he has also taught aviation subjects. His research fields included Dynamics, Thermodynamics and Aerodynamics (Politecnico di Torino, 2020). He authored a textbook titled "Meccanica applicata alle macchine" published by Levrotto \& Bella in Turin and divided into 3 volumes (Panetti, 1952). The textbook details the structure of the academic course of Applied Mechanics and the contents will reach the present day with few variations due to the progress of research in that field.

De facto, volumes one and two cover the foundation of Applied Mechanics from the kinematic analysis of planar mechanisms to the contact between bodies, friction and lubrication, to the study of mechanisms' theory and dynamics. The third volume focuses on flexible bodies and connections with application to funicular machines, probably due to a personal interest of Panetti in these research themes.

List of the contents according to a reprint of 1952 is reported in Table 3.

\subsection{The Structure of the Applied Mechanics Course}

The topics of the Applied Mechanics course have remained almost the same from the post-war period to today, or have undergone small variations. This is reflected in the structure of the textbooks of Applied Mechanics that still maintain an approach which is very well described by Enrico Pistolesi in the introduction to his book (Pistolesi, 1964), that divides it into four main sections. The first one is about the Fundamentals of Mechanics (FM): the kinematics of mechanisms (FM1), the contact forces between two bodies (friction and lubrication theory) (FM2), efficiency and equations of the dynamics (FM3). The second section deals with the Mechanism Theory (MT), i.e. the application of the tools developed in the previous part to the study of gears, bearings, brakes and flexible components. The third section focuses on dynamics of the machines (DM), extending the foundations of dynamics given in the first part to the rotating shafts analysis (DM1) and the control theory (DM2). Finally, the last section covers the Metrology (ME) that is strictly related to the experimental mechanics suggested in the declaratory. Table 4 summarizes the structure of the Applied Mechanics textbook proposed by Pistolesi.

Today, the structure of modern textbooks maintains the first two sections (Fundamentals of Mechanics and Mechanism Theory) and part of the third (the Dynamics of rotating shafts subsection), while the teaching of Control theory and Metrology have been often delegated to later specific SSDs (ING-INF/04Systems and control engineering and ING-IND/12-Mechanical and thermal measurements respectively). 
Table 3. Contents of Panetti's book: "Meccanica applicata alle Macchine" (Panetti, 1952).

\begin{tabular}{cc}
\hline Volume & Contents \\
\hline 1 & $\begin{array}{c}\text { Fundamentals of machine kinematics. Friction in machines. The resistance of the } \\
\text { medium. Fundamentals of machine dynamics. Mechanisms consisting of elementary } \\
\text { pairs. Rolling bearings. Helical couple. Mechanics of vibration in machines. }\end{array}$ \\
& $\begin{array}{l}\text { Wheel primitives. Cylindrical toothed profiles. Friction work in gears with parallel } \\
\text { axles. Gears for transmission between primitive competing axles and tapered } \\
\text { clutch pairs. Helical gears for transmissions between skewed axles. } \\
\text { Endless screwing pairs. Ordinary gearboxes. Epicyclic gearboxes. } \\
\\
\text { Ropes. Chains. Funicular machines. Funicular transport. } \\
\text { Tracked transmissions. Technical problems on transmissions. }\end{array}$ \\
\hline
\end{tabular}

Table 4. Structure of applied mechanics textbooks.

\begin{tabular}{cc}
\hline Main Section & Subsections \\
\hline Fundamentals of \\
Mechanics (FM) & Fundamental of kinematics (FM1) \\
Mutual contact forces between bodies \\
(friction and lubrication) (FM2) \\
Fundamentals of dynamics (work and efficiency, \\
equations of dynamics) (FM3)
\end{tabular}

\section{3. "The Masters" Period (1945-1980)}

The name of this period-"the masters"-emphasizes the unique figure of the full professor that was often the only author of the textbook, since he was the top manager of the entire research group on a specific matter for a specific university. De facto, the author's prestige reflected that of the university to which he belonged.

\subsection{Brief Historical Background}

The born of University in Italy dates back to the Middle Age with the University of Bologna (1088) which is considered the most ancient University still active today. In the 1940, there were 35 public universities and 4 private ones distributed throughout the Italian peninsula. During the Fascist period, the Gentile's ${ }^{1}$ reform of 1923 brought a drastic reduction in the number of university institutes. The universities were classified into two categories, those complete with all the faculties (Bologna, Cagliari, Genoa, Naples, Padua, Palermo, Pisa, Rome and ${ }^{1}$ Giovanni Gentile (1875-1944). 
Turin) were funded largely by the State, while the others received only a partial contribution from the State. Regarding the presence of full professors in the Italian University system, in 1939, there were 1.420 full professors, but at least half of the full professors were based in the seven major universities (Rome $11.8 \%$, Naples $8.2 \%$, Florence $6.8 \%$, Bologna $6.4 \%$, Turin $6.1 \%$, Milan $5.7 \%$ and Pisa 5.1\%). A further 30\% were located in the remaining universities in Genoa, Padua, Palermo, Pavia, Catania, Perugia, Messina and Bari ( $>2.5 \%$ each) (Rossi, 2016).

\subsection{Characteristics of the Textbooks}

The textbooks of this period are authored by the full professors of the main engineering universities, almost following the classification given by the Gentile's law.

A non-exhaustive list of these professors and corresponding University is given below in alphabetic order:

- Anastasio Anastasi-University of Rome (Anastasi, 1946)

- Antonio Agostino Capocaccia-University of Genoa (Capocaccia, 1949)

- Carlo Ferrari-Politecnico di Torino (Ferrari \& Romiti, 1966)

- Pericle Ferretti-University of Naples (Ferretti, 1966)

- Ettore Funaioli-University of Bologna (Funaioli, 1973)

- Modesto Panetti-Politecnico di Torino (Panetti, 1952)

- Enrico Pistolesi-University of Pisa (Pistolesi, 1964)

- Aristide Prosciutto-University of Bologna (Prosciutto, 1950)

- Mario Rubino-University of Palermo (Rubino, 1958)

- Giovanni Scotto Lavina-University of Rome (Scotto Lavina, 2016)

- Otorino Sesini-Politecnico di Milano (Sesini, 1946)

The distinctive feature of the textbook of this period is that the role and the prestigious of the authors are reflected in their textbooks. Like in modern bestsellers books, where the name of the author on the cover is more important than the title, since he/she guarantees a high level of publications. The contents partially follow the structure of Applied Mechanics books detailed in the previous section, since they are based on the research experience, teaching activity and knowledge of the authors themselves. Regarding the teaching activity, it is worth noting that it wasn't limited to Applied Mechanics course only, but they also taught in related fields, i.e. Prof. Prosciutto taught Machine Design, Fluid Machinery, Thermal Physics and Mechanical Technology.

As an example, Table 5 reports the percentage of pages dedicated to specific topics for few authors of this period. The acronyms are those detailed in Table 2. Taking as reference the book of Pistolesi, about $45 \%$ of the pages are dedicated to the Theory of Mechanisms (MT), 30\% to the Fundamentals of Mechanics (FM), 20\% to the Dynamics of Machines (DM), and the remaining 5\% to the Metrology (ME). Differences from this schema are mainly due to the influence of the author's research field: Capocaccia is mainly focused on friction and lu- 
brication (29\%) at the expense of kinematics study that are not included (Capocaccia, 1949). Conversely, Sesini gives strong foundations on kinematics analysis (28\%) but does not include the regulation theory and the metrology (Sesini, 1946). The textbook of Ferretti deserves a separate discussion (Ferretti, 1966): despite it consists of two volumes, the second one focuses on metrology only and it was written together with Mario Taddei (disciple and future author of an extended textbook in the next period (Taddei, 1982)). This volume was the reference textbook for another specific course on metrology at the University of Naples (Della Pietra, 2006). Percentages outside brackets refer to both the volumes, while percentages within brackets to the first volume only, i.e. the one specifically targeted for the fundamental course of Applied Mechanics. Again, Metrology was one of the main research areas of Ferretti and this is reflected on the textbook contents. More similar to the Pistolesi's book those of Prosciutto (Prosciutto, 1950) and Rubino (Rubino, 1958). The textbook of Scotto Lavina is divided into three parts, the first one covers the foundations of Applied Mechanics, the second one is dedicated to the dynamics of machines (42\%) while the third one is a collection of numerical examples that has not been considered in the computation of the percentages of pages (Scotto Lavina, 2016).

\section{4. "The Schools" (1980-2000) or "The Handbooks" (2000-Today) Period}

Unlike the previous one, this period has evolved and continues today. It started as "the schools" period, following the great changes that have occurred both at the Italian University system and within the group of professors pertaining to Applied Mechanics, as it will be detailed in the following historical backgrounds. The core part of the textbook is no more the single master/author, but the school (the research team) that each master had made grow. At the beginning of the new century a new reform of the Italian University system will ended the first part of this period, that evolves into the "the handbooks" one, that kept most of the characteristic features and it is still active today.

Table 5. Percentage of pages of the textbooks dedicated to specific topic (labels are given in Table 4). In Ferretti, the percentage within the brackets refers to the first volume only, while in Scotto Lavina only the first two volume has been considered $\left(^{\star}\right)$.

\begin{tabular}{|c|c|c|c|c|c|c|c|c|}
\hline \multicolumn{2}{|c|}{ Contents } & Capocaccia & Rubino & Ferretti & Sesini & Pistolesi & Prosciutto & Scotto Lavina* \\
\hline \multirow{3}{*}{ FM } & FM1 & $0 \%$ & $3.6 \%$ & $1.3 \%(2.9 \%)$ & $28 \%$ & $4.9 \%$ & $9 \%$ & $18.7 \%$ \\
\hline & FM2 & $28.8 \%$ & $7.4 \%$ & $4.4 \%(9.8 \%)$ & $22.4 \%$ & $16.2 \%$ & $12.3 \%$ & $13.2 \%$ \\
\hline & FM3 & $2 \%$ & $12.8 \%$ & $2.1 \%(4.7 \%)$ & $12.5 \%$ & $7.2 \%$ & $10.1 \%$ & $2.7 \%$ \\
\hline \multirow{3}{*}{ DM } & & $44 \%$ & $44.3 \%$ & $17.1 \%(38.3 \%)$ & $33.4 \%$ & $46.6 \%$ & $48.3 \%$ & $23.8 \%$ \\
\hline & DM1 & $0 \%$ & $13.7 \%$ & $13.6 \%(30.4 \%)$ & $3.7 \%$ & $10.6 \%$ & $9.3 \%$ & $25.8 \%$ \\
\hline & $\mathrm{DM} 2$ & $23.3 \%$ & $11.8 \%$ & $6.2 \%(13.9 \%)$ & $0 \%$ & $8.4 \%$ & $8.2 \%$ & $15.8 \%$ \\
\hline \multicolumn{2}{|c|}{ ME } & $1.9 \%$ & $6.4 \%$ & $55.3 \%(0 \%)$ & $0 \%$ & $6.1 \%$ & $2.8 \%$ & $0 \%$ \\
\hline
\end{tabular}




\subsection{Brief Historical Background}

From an historical point of view, the end of the century saw epochal changes in the Italian University, transforming it from an elite school to a modern institution of mass education. The number of students enrolled increased from 226,543 in the academic year 1950/51 to $1,474,719$ in 1991/92. The number of full professors increased from 3200 in 1970, to 9000 in 1981 and 13,169 in 1990. The number of Universities increased as well from 42 in 1970 to 72 in 2002 (considering both public and private ones). The milestone had been the born of modern academic department introduced by the Valitutti's law ${ }^{2}$ of 1980. A department is defined as an organization of one or more homogeneous research sectors that promotes and coordinates research activities. The university teaching had been structured on three academic figures: the researcher, the associate professor and the full professor. Finally, the law of May 9th 1989 sanctioned the organizational, didactic and financial autonomy of universities. They were responsible for their own development and could grow according to their ambitions and on the basis of the results obtained in the field of research and teaching.

\subsection{Characteristics of the Textbooks}

The teaching of Applied Mechanics also underwent profound changes in these years, which were also revealed in textbooks. The reorganization of universities into departments has promoted the creation of scientific disciplinary sectors (see Section 2.2) and their identity through the declarations. In fact, the first declaration of the SSD of Applied Mechanics was made in 1980 and was very different from the latter of 2013 (see Table 2), since it was a list of the academic courses related to its own research fields, as shown in Table 6. Few years later, in 1986, researchers of Applied Mechanics founded the Italian Group of Applied Mechanics (GMA from the Italian acronym), with the aim of maintaining contact with each other at a national level, coordinating on teaching and researching issues (Ceccarelli, 2014). The result was the structuring of applied mechanics and a homogeneity of the contents taught that was missing in the previous period.

Table 6. Declaration and competences of Applied Mechanics-1980 (Ceccarelli, 2014).

\begin{tabular}{|c|c|}
\hline Year & Text of Declaratory \\
\hline 1980 & $\begin{array}{l}\text { Reference courses: Assisted analysis of mechanical systems; fluid automation; } \\
\text { vibration and noise control; mechanical systems diagnostics; fundamentals } \\
\text { of mechanics applied to machines; drive mechanics; robot mechanics; } \\
\text { vehicle mechanics; mechanics of automatic machines; vibration mechanics; } \\
\text { mechatronics; modeling and simulation of mechanical systems; functional } \\
\text { mechanical design; regulation and control of mechanical systems; } \\
\text { experimentation on mechanical systems; lubrication theory } \\
\text { and technique; tribology. }\end{array}$ \\
\hline
\end{tabular}

${ }^{2}$ Salvatore Valitutti (1907-1992). 
With reference to textbooks, the main changes are:

- Contents homogeneity. Digressions on the research area of the authors are no more present, all the textbooks follow the structure of the fundamental course of Applied Mechanics detailed in Section 2.2, and the contents of textbooks are comparable to each other. This is probably the main consequence of the declaratory.

- Identity of the textbook. If the textbook of the previous period was a mirror of the master/author, now it is the mirror of the research group. The new organizational, didactic and financial autonomy of universities creates also competition between them. As a consequence, the prestige of the research group is more sought after than that of a single person and the textbook is the result of a collective work. For example, Jacazio and Piombo at the Politecnico di Torino (Jacazio \& Piombo, 1990), Funaioli, Maggiore and Meneghetti at the University of Bologna (Funaioli, Maggiore, \& Meneghetti, 1987), Ghigliazza and Galletti at the University of Genoa (Ghigliazza \& Galletti, 1984), or Guido and Della Pietra at the University of Naples (Guido \& Della Pietra, 1991).

- Number of authors. It increases accordingly to the number of full professors at University. In the previous period all the textbooks were authored by one person, now most publications are multi-author although the number of authors was related also to the size of research group or the local decisions. An example of one author textbook of this period is Taddei at the University of Naples (Taddei, 1982), or Cossalter at University of Padua (Cossalter, 1996).

- The aim of the textbook. This is a characteristic that will remain until today and that differentiates it very much from the following period. The textbook is, de facto, a handbook of Applied Mechanics. It is not written as notes of the professor's lectures, but it covers the whole subject of study. It is a reference text that the student will take with him/her during his/her career.

- Contents update. Despite the structure remains that of Pistolesi, the contents are updated to recent advances and some parts removed since no longer used in engineering practice. The metrology part is reduced, probably because it becomes the subject of thematic courses, while new technology advances like electromechanical actuation or cams for automatic machines are introduced and detailed.

- Mechanics of Vibration. A great change in the contents is the introduction of the mechanics of vibrations as a stand-alone part of the Applied Mechanics course. Vibrations were present also in the previous period, but as a subsystem of Dynamics. Now specific chapters and publications are proposed (Diana \& Cheli, 1993). The matrix notation is introduced to solve dynamics equations, a novel approach compared to the one used in previous publications. The introduction to computational and experimental modal analysis is probably favored by advances in computational software and hardware.

It is worth noting that new specialized courses are introduced in different universities beside to the fundamental course of Applied Mechanics, such as 
Mechanics of vibration, Tribology, Automation, etc. These new thematic courses will lead to an increase of publications in the years to come and the research area of Applied Mechanics will increase more (Magnani \& Ruggieri, 1986; Malvano \& Vatta, 1990; Ruggieri, 1998, Di Benedetto \& Pennestrì, 1999).

\section{3. "The Handbooks" Evolution}

Starting from 2000, a new period will take place in the textbooks evolution as it will be explained in the next section. Nevertheless, the "the schools" period evolves into "the handbooks" period that continues beside the new one. The main characteristic of "the schools" period drops and the University system is mature and steady. The urge to make a specific research group recognizable is no longer needed and the focus moves to the handbook function of the textbook, i.e. a reference text for the student during his/her studies and career. Recent publications (or reprints) of D'Agostino at the University of Salerno (D'Agostino, 2013), Belfiore, Di Benedetto, Pennestrì at University of Rome "Tor Vergata" (Belfiore, Di Benedetto, \& Pennestrì, 2005) or Della Pietra at the University of Naples "Federico II" (Della Pietra, 2011) must be considered part of this period.

\section{5. "The Courses" (2000-Today) Period}

The new century began with a new revolution in the Italian University systemthe last one so far-the consequences of which had repercussions on the textbooks of Applied Mechanics. The author named it "the courses" since the focus moves from the Applied Mechanics as a whole to its segmentation and its adaptation to the needs of academic courses.

\subsection{Brief Historical Background}

The Bassanini's ${ }^{3}$ reform (1997-1999) introduced the distinction between bachelor degree and master degree in Italian University system. Before it, the "laurea" degree comprised both bachelor and master in a five years course. Moreover, the reform aimed to guarantee the freedom to each university to build degree courses suited to the needs of the local economic and social reality. The degree courses designed by each university had to respect some general criteria in terms of objectives to be achieved and general aspects of the training activities, defined at national level. De facto, universities could create degree courses that were attractive to the local industrial production fabric and to students as well. In this period, very specialized degrees were born such as-in the engineering field for example-food engineering, mechatronics engineering, automation engineering or automotive engineering. On-line universities were equated with traditional ones, and the total amount of universities in Italy was 96 in 2015. The number of full-professors reached a peak of 19,618 units in 2007. The number of students increased: 1,060,274 in the academic year 1980/1981, 1,812,261 in 2008/ 2009 (Rossi, 2016).

${ }^{3}$ Franco Bassanini (1940). 


\subsection{Characteristics of the Textbooks}

The introduction of bachelor and master degrees led to a revision of the university educational offer. The aim of bachelor degree is giving foundations of the study course, while master degree is intended as a specialization is specific sectors. Since the student could stop his/her career at bachelor degree level, fundamental courses (e.g. Mechanical design or Electrical engineering) that usually were given at the fourth or fifth year now are moved to the second or third year. As a consequence, the duration of the courses is reduced and the contents revised, while new courses are proposed at the master degree covering those modern research topics that the fundamental course of Applied Mechanics was not used to include (biomechanics, robotics, diagnostics of machines, etc). The declaration of the SSD of Applied Mechanics is revised again as detailed in Table 7. With respect to the previous one (see Table 6), the focus shifted to the various research topics, often proposed into specific master's degree courses (Diana \& Resta, 2016; Legnani \& Fassi, 2003; Legnani \& Palmieri, 2016; Pennestrì, 2002; Rindi, Papini, Ignesti, Pugi, Auciello, \& Ridolfi, 2014, Ravina \& Scarafile, 2018, Rovetta, 2005). Textbooks of the previous period are no longer attractive for the students; academic lectures cover only a fraction of the whole book and often the costs were proportionately too high. Publisher soon sensed this market demand and encouraged the publication of new textbooks targeted on the characteristics of new academic courses. The length of the book is reduced and the contents match those of the academic lectures. The textbook of Applied Mechanics is no longer a handbook but the contents suite the academic course they refer to (Bachschmid, Bruni, Collina, Pizzigoni, \& Resta, 2003; Ciulli, 2013; Giordana, 2001; Mimmi \& Pennacchi, 2016; Pugi, 2020; Remino, 2014; Ruggieri \& Giberti, 2005). Some topics are not extended, as they are treated in other thematic publications. Regarding the mechanics of vibration, for example, only the case of one-degree of freedom is treated extensively, while often the n-degrees of freedom case is only mentioned. The extended treatment of these topics is carried out in the specific courses of Vibration Mechanics, which are followed by new publications

Table 7. Declaration and competences of Applied Mechanics-2001 (Ceccarelli, 2014).

Year Text of Declaratory
The sector includes the cultural and professional aspects inherent in the study of
mechanical systems using the methodologies of theoretical mechanics. The typology
of the studied machines is completely general; however, extensive reference is made to
driving and operating machines, mechanical devices, automatic machines and robots,
vehicles and biomechanical systems. In particular, both the analysis and the synthesis
of the mechanical behavior of the machines and systems indicated above are studied.
The analysis is divided into modeling, simulation, regulation and control of the same;
the synthesis is aimed at their functional design. Particular emphasis is placed on the
study of vibratory and tribological phenomena of machines. Strong interrelationships
are implemented with the methodologies and algorithms developed in the fields of
design and methods of industrial engineering, mechanical design and construction
of machines and fluid dynamics.


(Basso, 2014; Di Benedetto \& Belfiore, 2007; Fasana \& Marchesiello, 2006; Giovagnoni, 2009; Guido \& Della Valle, 2004).

Another distinctive feature of the textbooks in this period is the introduction of examples and exercises. They are an integral part of teaching and often the one that summarizes the contents in practical implication that the student remembers more easily. The teaching role became undoubtedly the main target of the textbooks. If in "the schools" period there was roughly one reference textbook for each University, now there can be more publications of the same research group, not only on different topics but also on the same. It is worth noting that in big universities, such as Politecnico di Torino, the need for different textbooks according to the different degree courses began to be felt earlier, proposing different textbooks for students with and without basic knowledge of theoretical mechanics (Belforte, 2007; Ferraresi \& Raparelli, 2007; Jacazio \& Pastorelli, 2001).

\subsection{A Unified Approach to Textbooks}

It is worth noting that the simultaneous presence of two different approaches to textbooks ("the handbook" and "the courses") led also to publications that merge together those characteristics. Some authors proposed extended treatise on Applied Mechanics-like in "the handbook" period-but structuring the contents into self-consistent chapters with examples and exercises-like in the "the courses" period. The result is a textbook that could be easily adapted to different courses and at different levels of detail (Callegari, Fanghella, \& Pellicano, 2013; Meneghetti, Maggiore, \& Funaioli, 2011). For example, the dynamics equations are introduced briefly in the first part of the textbook, and then deepen in later chapters. Sometimes the textbook is divided in different volumes and the student can buy only the one he/she is interested in.

\section{Future Prospects}

What does the future have to offer to the textbooks of Applied Mechanics? The Italian university system is stable and no drastic changes are on the horizon as in the past. The educational offer may change by expanding the number of specialized courses, but this change has been underway since 2000. The biggest change could come from the dematerialization of physical books. Most of the students follow the lectures recording the contents and transferring them to electronic documents they share within the students' community. More and more often, professors are offering their notes in PDF format on their course website. It is the evolution of "the courses" period, i.e. customization of the textbooks for that specific course and that specific academic year, since the contents could be changed easily and quickly. To support this prospect, Figure 1 shows the spread of textbooks in universities where Applied Mechanics is taught in 2020. In particular, for each public university the Mechanical Engineering degree (both at bachelor and master level) is taken as reference. The list includes all the textbooks 


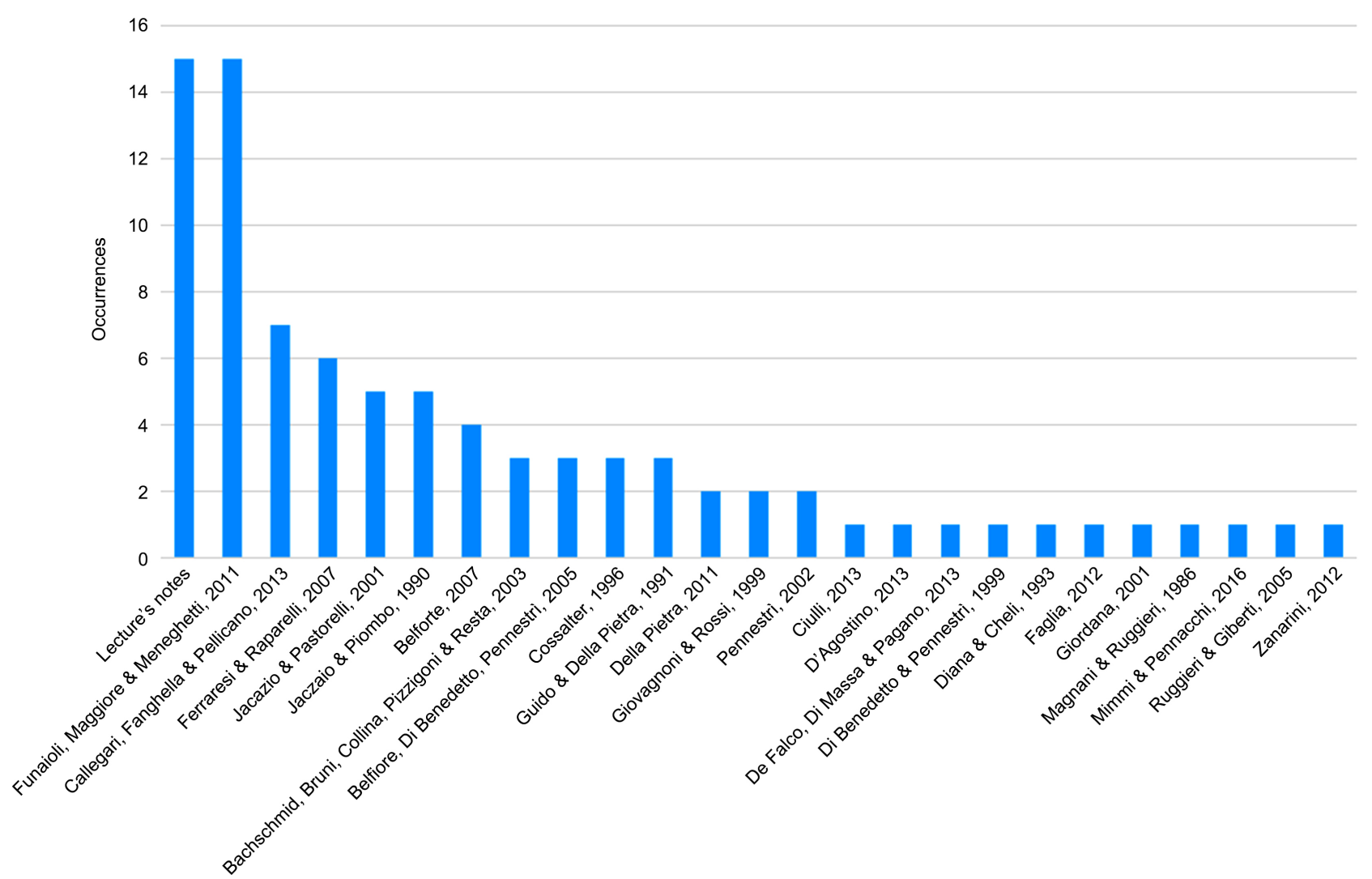

Figure 1. Occurrences of applied mechanics textbooks in mechanical engineering courses.

of Applied Mechanics officially inserted in the study plans. For those universities that don't offer Mechanical Engineering courses, a similar one was selected (e.g. Management engineering, Mechatronic engineering, etc.). The most common teaching aids are the teacher's notes. The podium is then completed by two textbooks that have been able to combine the contents of the two current periods (Meneghetti, Maggiore, \& Funaioli, 2011; Callegari, Fanghella, \& Pellicano, 2013). It worth noting that some publisher again sensed this market demand and the paper version of the textbook contains access code to dedicated on-line resources and/or electronic version of the book that the student could read on electronic devices. As a final remark, compare the first declaration of Applied Mechanics (1980), as shown in Table 6, and the last version (2013) shown in Table 2. The contents and the fields of application of Applied Mechanics increased exponentially through the decades. The passage from the masters and the schools period was characterized by a search for identity and unity of contents that can be included in a reference textbook and referring to a specific academic course: mechanical engineering. Currently, we are witnessing a reverse process: the differentiation of the Applied Mechanics, due to the current complexity and variety of research themes and the emergence of new scientific disciplines: Mechatronics, Nanotechnology, Management and Bioengineering, Laser technology, etc. Future papers about further evolutional steps cannot fail to consider the complex and numerous branches of the modern Applied Mechanics 
and their corresponding textbooks.

\section{Conclusion}

In this paper, the author proposes an excursus on the evolution of textbooks of Applied Mechanics in Italy from the postwar period to today. In particular, only the fundamental course of Applied Mechanics taught at the bachelor degree is considered. It is possible to identify characteristics common to many publications in given period, while these features change with time following the big changes of all Italian University system.

The textbooks considered span more than 60 years and they have been classified in three main classes or periods. The masters period that collects the first age of modern Italian University system, characterized by the personality of eminent full-professors who laid the foundations of the Applied Mechanics in Italy. The schools period saw the Italian University become mature, with several and relevant research groups distributed throughout the Italian territory, and a structural and organic reform of the Applied Mechanics whose influence continues today. Finally, the courses period is the actual one, the complexity and variety of research themes associated to Applied Mechanics led to a broad and detailed training offer and textbooks. The teaching commitment guides is the main purposes of these publications.

\section{Acknowledgements}

This paper is dedicated to the memory of Prof. Cesare Rossi (1955-2017). Distinguished full-professor of Applied Mechanics at the University of Naples "Federico II" and enthusiastic researcher on the history of mechanisms and machine science (Ceccarelli \& Gasparetto, 2020).

\section{Conflicts of Interest}

The author declares no conflicts of interest regarding the publication of this paper.

\section{References}

Anastasi, A. (1946). Meccanica applicata alle macchine. Roma: Dispense Universitarie Tumminelli.

Bachschmid, N., Bruni, S., Collina, A., Pizzigoni, B., \& Resta, F. (2003). Fondamenti di meccanica teorica e applicata. New York: McGraw-Hill.

Basso, R. (2014). Elementi di meccanica delle vibrazioni. Ed. Progetto.

Belfiore, N. P., Di Benedetto, A., \& Pennestrì, E. (2005). Fondamenti di meccanica applicata alle macchine. Milano: Casa Editrice Ambrosiana.

Belforte, G. (2007). Meccanica applicata alle macchine. Ed. Levrotto \& Bella.

Biggioggero, G. F., \& Rovida, E. (2014). Scuole di Meccanica. In V. Cantoni, V. Marchis, \& E. Rovida (Eds.), Storia della Meccanica (pp. 3-38). Padua: Pavia University Press.

Callegari, M., Fanghella, P., \& Pellicano, F. (2013). Meccanica applicata alle macchine. 
Milan: Ed. Città Studi.

Capocaccia, A. A. (1949). Meccanica applicata alle macchine (2 vols). Ed. Rodolfo Malfasi.

Ceccarelli, M. (2014). Breve storia della Meccanica Applicata alle macchine in Italia. In Proceedings of the Fifth National Congress on the History of Engineering (pp. 87-102). Naples.

Ceccarelli, M., \& Gasparetto A. (2020). Cesare Rossi (1955-2017). In M. Ceccarelli, \& Y. Fang (Eds.), Distinguished Figures in Mechanism and Machine Science (pp. 115-125). Cham: Springer. https://doi.org/10.1007/978-3-030-32398-1 7

Ciulli, E. (2013). Elementi di meccanica. Pisa: Ed. Pisa University Press.

Cocconcelli M. (2021). The Italian Textbooks of Mechanics Applied to Machines in the Modern Age. In V. Niola, \& A. Gasparetto (Eds.), Advances in Italian Mechanism Science. IFToMM ITALY 2020, Mechanisms and Machine Science, vol 91. (pp. 46-54). Cham: Springer. https://doi.org/10.1007/978-3-030-55807-9 6

Cossalter, V. (1996). Meccanica applicata alle macchine. Ed. Progetto.

D’Agostino, V. (2013). Fondamenti di meccanica applicata alle macchine. Ed. Maggioli.

De Falco, Di Massa, Pagano (2013). Cinematica e dinamica del corpo rigido. Ed. Lulu.

Della Pietra, L. (2006). La Meccanica Applicata alle Macchine a Napoli. In Proceedings of the First National Congress on the History of Engineering (pp. 617-634). Naples.

Della Pietra, L. (2011). Lezioni di meccanica applicata alle macchine (2 vols). EdiSES.

Di Benedetto, A., \& Belfiore, N. P. (2007). Fondamenti di teoria delle vibrazioni meccaniche. Milano: Casa Editrice Ambrosiana.

Di Benedetto, A., \& Pennestrì, E. (1999). Introduzione alla cinematica dei meccanismi (3 vols). Milano: Casa Editrice Ambrosiana.

Diana, G., \& Cheli, F. (1993). Dinamica e vibrazioni dei sistemi meccanici (2 vols). Torino: UTET.

Diana, G., \& Resta, F. (2016). Controllo di sistemi meccanici. Ed. Polipress.

Faglia, R. (2012). Modelli elementari per la meccanica applicata. Ed. Esculapio.

Fasana, A., \& Marchesiello, S. (2006). Meccanica delle vibrazioni. Ed. CLUT.

Ferraresi, C., \& Raparelli, T. (2007). Meccanica applicata. Ed. CLUT.

Ferrari, C., \& Romiti, A. (1966). Meccanica applicata alle macchine. Torino: UTET.

Ferretti, P. (1966). Meccanica delle macchine (2 vols). Ed. Liguori.

Funaioli, E. (1973). Meccanica applicata alle macchine (2 vols). Ed. Patron.

Funaioli, E. (1998). L'Istituto di Meccanica applicata alle macchine dell'Università di Bologna. Bologna: Academic Session of April 29, 1998.

Funaioli, E., Maggiore, A., \& Meneghetti, U. (1987). Lezioni di meccanica applicata alle macchine (2 vols). Ed. Patron.

Ghigliazza, R., \& Galletti, C. U. (1984). Meccanica applicata alle macchine. Torino: UTET.

Giordana, F. (2001). Lezioni di meccanica delle macchine. Edizioni Spiegel.

Giovagnoni, M. (2009). Analisi delle vibrazioni nei sistemi meccanici. Libreria Cortina.

Giovagnoni, M., \& Rossi, A. (1999). Una introduzione allo studio dei meccanismi. Libreria Cortina.

Guido, A. R., \& Della Pietra L. (1991). Lezioni di meccanica delle macchine (2 vols). CUEN.

Guido, A. R., \& Della Valle, S. (2004). Vibrazioni meccaniche nelle macchine. Liguori editore. 
IFToMM (2020). International Federation for the Promotion of Mechanism and Machine Science. http://iftomm.net/

Jacazio, G., \& Pastorelli, S. (2001). Meccanica applicata alle macchine. Torino: Ed. Levrotto $\&$ Bella.

Jacazio, G., \& Piombo, B. (1990). Meccanica applicata alle macchine (4 vols). Torino: Ed. Levrotto \& Bella.

Legnani, G., \& Fassi, I. (2003). Robotica industriale. Milano: Casa Editrice Ambrosiana.

Legnani, G., \& Palmieri, G. (2016). Fondamenti di meccanica e biomeccanica del movimento. Milan: Ed. Città Studi.

Magnani, P. L., \& Ruggieri, G. (1986). Meccanismi per macchine automatiche. Torino: UTET.

Malvano, R., \& Vatta, F. (1990). Fondamenti di lubrificazione. Torino: Levrotto \& Bella.

Meneghetti, U. (2016). L'insegnamento della Meccanica Applicata alle Macchine nell'Università di Bologna. Bologna: Reports of the Conferences of the School of Engineering and Architecture.

Meneghetti, U., Maggiore, A., \& Funaioli, E. (2011). Lezioni di meccanica applicata alle macchine (3 vols). Ed. Patron.

Mimmi, G., \& Pennacchi, P. (2016). Appunti di meccanica applicata alle macchine. Libreria Universitaria Medea.

Panetti, M. (1952). Meccanica applicata alle macchine (3 vols). Ed. Levrotto \& Bella.

Pennestrì, E. (2002). Dinamica tecnica e computazionale (2 vols). Milano: Casa Editrice Ambrosiana.

Pistolesi, E. (1964). Meccanica applicata alle macchine. Rome: Ed. Tecnico Scientifica.

Politecnico di Torino (2020). Virtual Museum of the Politecnico di Torino. https://areeweb.polito.it/strutture/cemed/museovirtuale/storia/2-02/2-2-03/2-2-0346.htm

Prosciutto, A. (1950). Elementi di meccanica applicata alle macchine. Ed. Patron.

Pugi, L. (2020). Fondamenti di meccanica applicata. Ed. Esculapio.

Ravina, E. \& Scarafile, G. (2018). Problemi di meccanica applicata alla nave. Genova: Genova University Press.

Remino, C. (2014). Fondamenti di meccanica applicata. Ed. Libreria Universitaria.it.

Rindi, A., Papini, S., Ignesti, M., Pugi, L., Auciello, J., \& Ridolfi, A. (2014). Lezioni di meccanica del veicolo. Ed. Esculapio.

Rossi, P. (2016). Stato Giuridico, Reclutamento ed Evoluzione della Docenza Universitaria (1975-2015). RT. A Journal on Research Policy \& Evaluation, 1, 1-14.

Rovetta, A. (2005). Robotica. Ed. Hoepli.

Rubino, M. (1958). Meccanica applicata alle macchine. San Diego, CA: Ed. Giuseppe Principato.

Ruggieri, G. (1998). Appunti di problemi speciali di meccanica. Ed. Spiegel.

Ruggieri, G., \& Giberti, H. (2005). Fondamenti di meccanica per l'ingegneria. Maggioli Editore.

Scotto Lavina, G. (2016). Meccanica applicata alle macchine (3 vols, Reprint of 1983 Edition). Ed. Efesto.

Sesini, O. (1946). Meccanica applicate alle macchine (5 vols). Milano: Casa Editrice Ambrosiana.

Taddei, M. (1982). Meccanica applicata alle macchine (3 vols). Napoli: Edizioni Liguori. 
Universitaly (2020). The Website of the Italian Ministry of Education, University and Research. https://www.universitaly.it/index.php/

Zanarini, A. (2012). Analisi cinetostatica grafica di meccanismi piani. Ed. Esculapio. 